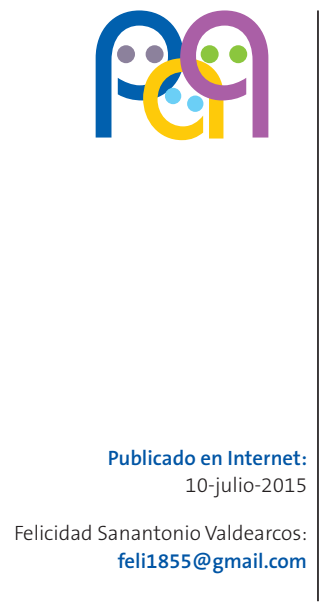

Palabras clave:

- TIBOLA

- Rickettsia slovaca - Picadura de garrapata

\title{
TIBOLA: enfermedad emergente producida por picadura de garrapata
}

\author{
F. Sanantonio Valdearcos ${ }^{a}$, M. C. Otero Reigadab \\ aPediatra. CS Vilamarxant. Valencia. España • ' Servicio de Pediatría. Hospital Universitario
} La Fe. Valencia. España.
ป Las enfermedades trasmitidas por garrapatas son poco frecuentes en nuestro medio. Presentamos un caso de linfadenopatía por picadura de garrapata (TIBOLA, por su nombre en inglés: tick-borne lymphadenopathy). Es una enfermedad emergente causada por Rickettsia slovaca. Se manifiesta como una escara necrótica en cuero cabelludo, en el lugar de la picadura, fiebre y múltiples adenopatías craneales y laterocervicales posteriores. La duración media del periodo de incubación desde la picadura es de siete días.
Ante un paciente con adenitis cervical y el antecedente de picadura de garrapata y/o escara en el cuero cabelludo el diagnóstico de TIBOLA es el más frecuente.

\section{TIBOLA: an emergent disease caused by tick bite}

\begin{tabular}{|c|c|}
\hline 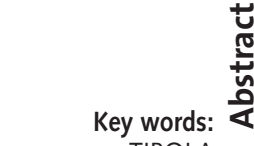 & $\begin{array}{l}\text { Tick-borne diseases are rare in our environment. We describe a case of tick-borne lymphadenopathy } \\
\text { (TIBOLA), an emergent disease caused by Rickettsia slovaca. The patients have a necrotic eschar on } \\
\text { the scalp, at the site of a bite, fever and multiple occipital and/or cervical lymphadenopathies. The } \\
\text { medium duration of incubation since the bite is seven days. }\end{array}$ \\
\hline $\begin{array}{r}\bullet \text { TIBOLA } \\
\bullet \text { Rickettsia slovaca } \\
\bullet \text { Tick bite }\end{array}$ & $\begin{array}{l}\text { In the case of a patient with cervical adenitis and history of tick bite and/or eschar scalp, the diagnosis } \\
\text { of TIBOLA is the most common. }\end{array}$ \\
\hline
\end{tabular}

\section{CASO CLÍNICO}

Niña de 18 meses que consultó por una picadura de garrapata en la cabeza detectada 24 horas antes. La madre cree que pudo suceder 3-4 días antes, pues hicieron una salida al campo (mes de abril). No convivían con ellos animales domésticos (perros ni otras mascotas). La garrapata la retiraron manualmente, y era de unos $5 \mathrm{~mm}$ de diámetro. El día de la consulta inició fiebre y le notan unos bultos en la cabeza.
En la consulta, a la exploración presentaba buen estado general, aunque estaba irritable y algo decaída. En región parietoccipital izquierda se apreciaba una escara negruzca de unos $7 \mathrm{~mm}$ de diámetro con eritema leve. En el cráneo presentaba múltiples adenopatías mastoideas y cervicales posteriores de pequeño tamaño entre 1 y 1,5 cm de diámetro, ligeramente dolorosas a la palpación. El resto de exploración era normal y no presentaba exantemas.

En un primer momento se solicitó una analítica para estudio de picadura de garrapata y se recomendó 
tratamiento con amoxicilina-clavulánico pensado en una posible sobreinfección de la picadura.

Controlada una semana después, persistía la escara, las adenopatías y la fiebre, los resultados de los análisis mostraron una leucocitosis con aumento de la velocidad de sedimentación globular (VS) hasta $20 \mathrm{~mm} / \mathrm{h}$ y proteína $C$ reactiva $(\operatorname{PrCR})$ de $10 \mathrm{mg} / \mathrm{dl}$, las serologías de Borrelia burgdorferri y Rickettesia connori fueron negativas. Ante la mala evolución del cuadro y por sospecha de rickettsiosis, se consultó el caso con los especialistas en enfermedades infecciosas de nuestro hospital de referencia y se decide tratamiento con ciprofloxacino oral, solicitándose nueva analítica con serología.

La paciente es controlada una semana más tarde, estando ya afebril y con buena evolución de las adenopatías, que regresan lentamente, solo persiste una pequeña zona de alopecia de unos $2 \mathrm{~cm}$ de diámetro. En la analítica de control se apreciaba una disminución de la leucocitosis y la VS.

El segundo control serológico diez días después mostraba un título de $R$. connori: IgG $\leq 1: 40$ e IgM 1:320. No se pudo remitir muestra para estudio de R. slovaca.

A los dos meses la niña estaba asintomática y la serología mostraba títulos en descenso frente a $R$. connori $\lg \mathrm{G}$ 1:40 e $\lg M \leq 1: 40$.

\section{DISCUSIÓN}

En los últimos años, dentro de las enfermedades emergentes están apareciendo nuevas enfermedades transmitidas por picadura de garrapata. Algunas están producidas por nuevas especias de Borrelia y otras por Rickettsias ${ }^{1,2}$. Entre estas últimas está la enfermedad producida por Rickettsia slovaca, que se conoce como tick-borne lymphadenopathy (TIBOLA) o dermacentor-bone, necrosis, erithema, lymphadenopathy (DEBONEL).

La primera descripción de esta enfermedad fue en 1997: se trataba de una mujer que había estado en la zona de los Pirineos y que presentaba una escara negruzca en cuero cabelludo, adenopatías occipitales y síntomas generales ${ }^{3}$. Esta enfermedad se produce siempre tras la picadura de una garrapata de la especie Dermacentor, que es habitual en la Península Ibérica y otras zonas de Francia. Se aisló por primera en Eslovaquia, en $1968^{4}$.

Esta especie de garrapata vive en mamíferos de pelo largo, vacas, cabras y ovejas en su época adulta, que es en invierno, mientras que en sus estadios más inmaduros, durante la primavera, vive en roedores ${ }^{5}$. En nuestro medio, el contagio es más frecuente en primavera y algo menos en invierno. Por su predilección por el pelo largo, se cree que es más frecuente entre mujeres y niños, afectando siempre a la parte superior del cuerpo y sobre todo a la cabeza.

Tras la picadura de la garrapata, con un periodo de incubación de unos siete días, se presenta el cuadro clínico característico. Comienza con una escara al principio amarillenta y melicérica que luego pasa a negruzca por la necrosis; además, se van presentando múltiples adenopatías occipitales y cervicales posteriores de 1-1,5 cm de diámetro, bastante dolorosas, junto con cefalea, decaimiento y, en aproximadamente la mitad de los casos, fiebre ${ }^{6}$.

La analítica suele ser normal, en algunos casos puede aparecer leucocitosis, leucopenia y/o trombopenia. En cuanto a la serología, es muy frecuente que tenga reacciones cruzadas con diversas especies de Rickettsia, como R. connori, como en nuestro $\mathrm{caso}^{7}$. El diagnóstico definitivo se practica en laboratorios especializados donde se realiza serología para $R$. slovaca y reacción en cadena de la polimerasa (PCR) específica, que en nuestra paciente no se pudo realizar.

En cuanto al tratamiento, hay escasa experiencia; en principio se cree que lo más adecuado sería doxiciclina durante diez días en mayores de ocho años y un macrólido (azitromicina o claritromicina) en menores de ocho años.

El objetivo de esta nota clínica es dar a conocer esta enfermedad que puede ser fácilmente confundida con una impetiginización de la picadura de garrapata, como nos pasó en este caso. Ante un paciente con adenitis cervical y el antecedente de picadura de garrapata y/o escara en el cuero cabeIludo el diagnóstico de TIBOLA es el más frecuente. 


\section{CONFLICTO DE INTERESES}

Los autores declaran no presentar conflictos de intereses en relación con la preparación y publicación de este artículo.

\section{BIBLIOGRAFÍA}

1. Raoult D, Lakos A, Fenollar F. Spotless Ricekttsiosis caused by Rickettsia slovaca and associated with dermacentor ticks. Clin Infect Dis. 2002;34:1331.

2. Sexton DJ. Other spotted fever group rickettsial infections. En: UpToDate [en línea] [consultado el 09/07/2015]. Disponible en www.uptodate.com/ contents/other-spotted-fever-group-rickettsial-infections

3. Raoult D, Derbis P, Roux V, Xu W, Maurin M. A new tick-transmited disease due to Rickettsia slovaca. Lancet. 1997;350;112-3.

\section{ABREVIATURAS}

DEBONEL: dermacentor-bone, necrosis, erithema, lymphadenopathy $\bullet$ PCR: reacción en cadena de la polimerasa - PrCR: proteína $C$ reactiva - TIBOLA: tick-borne lymphadenopathy - VS: velocidad de sedimentación globular.

4. Rehacek J. Rickettsia slovaca, the organism and its ecology. Acta SC Nat Brno. 1984;18:1-50.

5. Márquez-Jiménez FJ, Hidalgo Pontiverosa A, Rodríguez Liébana JJ, Muniain-Ezcurra MA. Las garrapatas (Acerina: Ixodida) como transmisores y reservorios de microorganismos patógenos en España. Enfer Infecc Microbiol Clin. 2005;23:94-102.

6. Lakos A. Tick borne lymphadenopathy a new rickettsial disease? Lancet. 1997;350:1006.

7. Lakos A. Tick borne lymphadenopathy (TIBOLA). Wein Klin Wochenschr. 2002;114:648-54. 